\title{
A simple adherence test for detection of IgM antibodies in typhoid
}

\author{
L. Y. ONG, T. PANG*, S. H. LIM, E. L. TAN and S. D. PUTHUCHEARY*
}

Department of Genetics and Cellular Biology and "Department of Medical Microbiology, University of Malaya, 59100 Kuala Lumpur, Malaysia

\begin{abstract}
Summary. A simple adherence test to detect IgM antibodies in patients with typhoid is described. The test utilises the IgM-"capture" approach, in which the test serum is applied to microtitration plate wells previously coated with anti-human IgM, followed by application of a stained Salmonella typhi antigen suspension which shows adherence in positive cases. By this test, $58(95 \%)$ of 61 sera from confirmed cases of typhoid possessed IgM antibodies to the $\mathrm{H}$ or $\mathrm{O}$ or both antigens of $S$. typhi. In patients for whom a diagnosis of typhoid was based only on a significant Widal-test titre, $31(41 \%)$ of 76 sera had IgM antibodies to the $\mathrm{H}$ or $\mathrm{O}$ or both antigens of $S$. typhi. Some cross-reactivity of the IgM antibodies was detected, especially with the $O$ antigens of $S$. paratyphi A and B. A total of 82 sera from non-typhoidal fevers (leptospirosis, typhus, dengue fever) showed no reactivity in this test. In normal sera there was no detectable IgM to the $\mathrm{O}$ antigen of $S$. typhi and only a small number $(3.9 \%)$ had low levels of IgM to the $\mathrm{H}$ antigen. The significance and potential importance of this simple, sensitive, specific and economical test is discussed.
\end{abstract}

\section{Introduction}

Typhoid remains an important public health problem in many parts of the tropical world, including Malaysia, which had nearly 3000 cases in 1987. Definitive diagnosis of typhoid relies upon successful isolation of the causative organism from patients' specimens such as blood, stool and urine. In addition, especially in situations where relevant facilities for culture are not available, serological tests such as the Widal test are often used as additional diagnostic aids. The many limiting factors affecting the Widal test are well-knowne.g., the stage of illness, the normal population titres in endemic areas, the effects of vaccination, non-specific cross-reactions, anamnestic response, antibiotic therapy and technical factors. These limitations often lead to difficulties in the interpretation of Widal test results. Furthermore, for a meaningful result, the test requires the availability of paired sera; the result on a single specimen is often inconclusive. It has been stated that a rapid immunodiagnostic test for typhoid which is sensitive, specific, simple, rapid and economical does

Received 5 Sep. 1988; revised version accepted 12 Jan. 1989.

*Correspondence should be sent to Dr T. Pang, Department of Medical Microbiology, University of Malaya, 59100 Kuala Lumpur, Malaysia. not yet exist (Edelman and Levine, 1986). Therefore, a simple test capable of reliably detecting IgM antibodies to Salmonella typhi would be a useful adjunct to existing tests, as it would presumably indicate recent or ongoing infections. One approach used in the detection of specific IgM antibodies is the IgM-'capture' approach in which anti-human IgM adsorbed to a solid phase is used to bind selectively IgM present in examined sera and thus eliminate competition by other antibody classes in the subsequent testing (Ryan and Kwasnik, 1985). We report here the development of such a test-a simple, specific and economical method to detect IgM antibodies in cases of typhoid, using the IgM"capture" approach and involving adherence of stained $S$. typhi antigen suspensions in the final stage.

\section{Materials and methods}

\section{Sera}

Four groups of serum samples were collected from different sets of individuals.

Group 1 consisted of 61 single samples of serum from patients with a clinical diagnosis of typhoid admitted to the University Hospital, Kuala Lumpur. These sera had Widal-test titres of $\geqslant 640$ (for both $\mathrm{H}$ and $\mathrm{O}$ antigens). 
The diagnosis of typhoid in these patients was confirmed by the isolation of $S$. typhi from blood or faeces, or both. The date of onset of clinical symptoms varied from 3-4 days to 6-7 weeks.

Group 2 consisted of 76 single samples of serum from patients in whom the diagnosis of typhoid was based on a significant titre in the Widal test $(\geqslant 640$ to $\mathrm{H}$ or $\mathrm{O}$ antigen, or both) but without confirmation by isolation of S. typhi.

Group 3 consisted of 82 single samples of serum from patients with non-typhoidal fevers common in the study region-leptospirosis (20), typhus (42) and dengue fever (20). Leptospirosis was diagnosed by the microscopic agglutination test (Alexander, 1976), typhus by the WeilFelix reaction to Proteus OXK, OX19 and OX2 antigens (Felix, 1944) and dengue fever by virus isolation (Lam et al., 1986) or haemagglutination inhibition (Clarke and Casals, 1958).

Group 4 consisted of sera from 102 healthy individuals from the medical-student population of the University of Malaya.

\section{Antigens}

Antigen suspensions comprised stained, killed $\mathbf{H}$ and $\mathrm{O}$ antigens from $S$. typhi, S. paratyphi A, S. paratyphi B and Proteus OXK, OX19 and OX2 (Wellcome Reagents Ltd, Kent).

\section{Widal-test}

The Widal test on various sera was performed by standard procedures, as described previously (Pang and Puthucheary, 1983).

\section{Adherence test to detect IgM}

The adherence test to detect IgM to $S$. typhi was performed by adding $100 \mu \mathrm{l}$ of rabbit anti-human IgM ( $\mu$ chain-specific, Dako Immunochemicals, Copenhagen, Denmark) at a dilution of 400 in borate-saline buffer (pH 9.0) to wells of U-bottom microtitration plates (Immulon 2, Dynatech Laboratories, Alexandria, VA, USA). The dilution of $\mathbf{4 0 0}$ was decided after testing the antisera at various dilutions from 100 to 1600 . After overnight incubation at $4^{\circ} \mathrm{C}$, coated plates were washed three times with distilled water containing Tween $20(0.05 \%)$ and tapped dry. Plates prepared in this manner can be stored at $4^{\circ} \mathrm{C}$ for up to 4 months. Patients' sera were then serially diluted in the anti-human IgM-coated plates in normal saline, starting with an initial dilution of $80(100 \mu \mathrm{l}$ final volume/well). Plates were then incubated for $2 \mathrm{~h}$ at $37^{\circ} \mathrm{C}$, washed three times with distilled water and tapped dry. Then $50 \mu \mathrm{l}$ of antigen suspension (diluted approximately 1 in 16 in normal saline) was added to the wells and the plates were incubated further at $37^{\circ} \mathrm{C}$ for $4 \mathrm{~h}$ (for $\mathrm{O}$ antigen) and overnight (for $\mathrm{H}$ antigen). Plates were then read by means of a microtitre mirror (Cooke Engineering Co., Alexandria, VA, USA). A positive result was shown by formation of an adherence pattern, whereas a "button" indicated the absence of IgM antibody.

\section{IgM abolition by 2-mercaptoethanol treatment}

For removal of IgM from selected sera, $20 \mu \mathrm{l}$ of 2mercaptoethanol (2-ME; Sigma Chemical Co., St Louis, MO, USA) was mixed with an equal volume of the serum and the mixture was incubated for $1 \mathrm{~h}$ at $37^{\circ} \mathrm{C}$ and then tested for IgM as described above.

\section{IgM removal by immunobeads}

Samples $(100 \mu \mathrm{l})$ from selected sera were pre-incubated with an equal volume of anti-human IgM-coated immunobeads (BioRad Laboratories, Richmond, CA, USA), at a concentration of $1 \mathrm{mg} / \mathrm{ml}$ in borate-saline buffer, at $4^{\circ} \mathrm{C}$ for $1 \mathrm{~h}$. Sera were then tested in the usual manner.

\section{Results}

Of the 61 Group-1 sera from confirmed cases of typhoid, as indicated by isolation of $S$. typhi, 58 $(95 \%)$ had IgM antibodies to the $\mathrm{H}$ or O, or both, antigens of $S$. typhi by our test (table I). Within this group, $51(84 \%)$ had IgM antibodies to both $\mathrm{H}$ and $\mathrm{O}$ antigens, six $(10 \%)$ to only the $\mathrm{H}$ antigen and one $(2 \%)$ to only the $\mathrm{O}$ antigen. Of the $58 \mathrm{IgM}$-positive sera in this group, more than $80 \%$ had IgM titres of $\geqslant 1280$ (table II). In a random sample of ten of

Table I. Levels of IgM antibody to $S$. typhi in various groups of sera

\begin{tabular}{rlcc}
\hline Group & \multicolumn{1}{c}{ Category } & $\begin{array}{c}\text { Number of sera } \\
\text { in group }\end{array}$ & $\begin{array}{c}\text { Number IgM } \\
\text { positive* }\end{array}$ \\
\hline 1 & Typhoid (confirmed) & 61 & $58(95 \%)$ \\
2 & Typhoid (serology only) & 76 & $31(41 \%)$ \\
3. & Other fevers & 82 & 0 \\
4 & Normal & 102 & $4(3.9 \%)$ \\
\hline
\end{tabular}

* Positive to $S$. typhi $\mathrm{H}$ or $\mathrm{O}$ antigens, or both, at a titre of $\geqslant 80$.

Table II. Titres of IgM antibodies to $S$. typhi $\mathrm{H}$ and $\mathrm{O}$ antigens in the 58 positive Group- 1 sera by the adherence test

\begin{tabular}{l|cc}
\hline \multirow{2}{*}{ Titre range } & \multicolumn{2}{|c}{ Number of sera reacting to } \\
\cline { 2 - 3 } & H antigen & O antigen \\
\hline $80-640$ & $8(14 \%)$ & $10(17 \%)$ \\
$1280-5120$ & $40(69 \%)$ & $34(59 \%)$ \\
$\geqslant 10240$ & $10(17 \%)$ & $14(24 \%)$ \\
\hline
\end{tabular}


these IgM-positive sera-nine with titres of 1280 $\geqslant 10240$ ( $\mathrm{O}$ and $\mathrm{H}$ antigens) and one of $320(\mathrm{O})$, $640 \mathrm{H}$-treatment for removal of $\operatorname{IgM}$ by $2-\mathrm{ME}$ resulted in marked falls in the $\mathrm{O}$ and $\mathrm{H}$ titres, measured by our method, to undetectable levels, except for one serum, which nevertheless showed a very large reduction, from $\geqslant 10240$ to $640(\mathrm{O}), 320$ (H). Similar results were obtained by treatment of the same set of sera with anti-human IgM-coated immunobeads, as used in earlier dengue virus IgM studies (Gunasegaran et al., 1986). These 10 sera all gave negative results in the latex agglutination test for rheumatoid factors (Winchester, 1976). Of 42 sera from Group 1 showing IgM to $S$. typhi $\mathrm{H}$ antigen, two $(5 \%)$ cross-reacted with the $\mathrm{H}$ antigen of $S$. paratyphi A and one $(2 \%)$ cross-reacted with the $\mathrm{H}$ antigen of $S$. paratyphi $\mathrm{B}$. All three crossreacting sera had higher IgM titres to $S$. typhi than to $S$. paratyphi A or B. Of 39 Group-1 sera showing reactivity to $S$. typhi $\mathrm{O}$ antigens, $13(33 \%)$ showed various degrees of cross-reactivity to the $\mathrm{O}$ antigens of $S$. paratyphi A and B and, of these, five showed a high degree of cross-reactivity (titres $\geqslant 10240$ ) to the $\mathrm{O}$ antigen of $S$. paratyphi A or B.

In Group 2, for which a diagnosis of typhoid was based solely on a significant Widal-test titre, 31 $(41 \%)$ out of 76 sera tested had IgM antibodies to $\mathrm{H}$ or O, or both, antigens of $S$. typhi (table I). In Group 3, none of the sera from patients with leptospirosis (20), or typhus (42) or dengue fever (20) reacted with $S$. typhi in this test (table I). Similarly, none of the 102 normal sera tested (Group 4) showed detectable levels of IgM antibody to the $\mathrm{O}$ antigen of $S$. typhi and only four $(3.9 \%)$ had a measurable titre against the $\mathrm{H}$ antigen (table I).

\section{Discussion}

An important approach to the rapid diagnosis of infectious diseases is the detection of specific IgM antibodies, the presence of which is usually indicative of a recent or ongoing infection (Ryan and Kwasnik, 1985). Other studies have shown a significant increase in IgM levels (as measured by single radial diffusion) in patients with typhoid, at all stages of the illness, from the first week onwards (Kumar et al., 1974). The IgM-adherence method that we have described provides a simple, sensitive, specific and economical test to detect IgM class antibodies in typhoid. The test is economical in using readily available and inexpensive materials and reagents and in its lack of dependence on sophisticated instrumentation. The test was able to detect $\operatorname{IgM}$ in $95 \%$ of confirmed typhoid cases and no false-positives were detected in sera from other, non-typhoidal fevers common in the region, viz. typhus, leptospirosis and dengue fever. In comparison, other studies based on an ELISA approach detected IgM to the LPS antigen of $S$. typhi in $81.8 \%$ (Srivastava and Srivastava, 1986) and 93.1\% (Nardiello et al., 1984) of proven cases of typhoid. In retrospect, it would have been useful to have included the ELISA approach in the present study for the purpose of comparison and this should probably be considered in any future similar investigations. Among the three typhoid patients whose sera showed no detectable IgM in the present study, one had been treated with chloramphenicol and other was admitted 2 months after the onset of symptoms, by which time the IgM levels may have dropped to an undetectable level. In relation to this, it is known that early chemotherapy can suppress antibody formation in typhoid cases (Watson, 1957) and that IgM levels may have subsided after 45-90 days (Nardiello et al., 1984). If these two cases are excluded from the group, 58 of the remaining 59 sera $(98 \%)$ had detectable IgM by this test. As expected, the present study showed cross-reactivity of the IgM antibodies, especially with the $\mathrm{O}$ antigens of $S$. typhi-related organisms ( $S$. paratyphi $A$ and $B$ ) due to the sharing of antigenic component 12 (Christie, 1980).

The present study also suggests that the IgMadherence test is likely to be helpful in interpreting a single, high-titre Widal test result when isolation of the causative organism is unsuccessful or not attempted. The presence of IgM antibodies in $41 \%$ of the sera in this group would provide further diagnostic support for a diagnosis of typhoid in such cases. However, explanations are needed for the remaining, IgM-negative sera in this category. It could be questioned whether they are real cases of typhoid, but if so, it is possible that the IgM level in these sera may have been below the sensitivity limit of the IgM-adherence test. This seems unlikely, in view of the fact that IgM was detectable in $95-98 \%$ of confirmed typhoid cases and that the patients' characteristics for the two groups (i.e., age, date of onset, etc.) were similar. The more likely possibility is that these patients were suffering from other febrile illnesses and that the elevated Widal-test titres were thus a result of an anamnestic response. Wicks et al. (1974) have suggested that high Widal titres at the early stages of typhoid in an endemic area represented an anamnestic response. It has been suggested that anti-H antibody, in particular, is anamnestically responsive and easily stimulated by non-specific stimuli (Christie, 1980). Our results with these sera, which showed high titres in the Widal test but which were negative 
by isolation, also caution against making a diagnosis of typhoid based on a single, elevated titre in the Widal test.

It seems likely that our test for detecting IgM to $S$. typhi should prove an important additional method in the laboratory diagnosis of typhoid. In relation to other methods previously used for this purpose, such as ELISA (Nardiello et al., 1984; Srivastava and Srivastava, 1986), crossed-immunoelectrophoresis (Tsang and Chau, 1981) and radio-immunoassay (Tsang et al., 1981), the IgMadherence test is superior in being economical and simple to perform and in utilising non-hazardous materials and not requiring sophisticated instruments. Furthermore, it has the important advantage of being applicable even when only a single serum specimen is available. In our experience, about 70 $80 \%$ of sera submitted for typhoid diagnosis are single specimens. Furthermore, in endemic areas such as Malaysia, antibody titres may rise very rapidly because of previous exposure and therefore demonstration of rising titres between two speci-

\section{REFERENCES}

Alexander A D 1976 Serological diagnosis of leptospirosis. In: Rose N R, Friedman H (eds) Manual of clinical immunology. American Society for Microbiology, Washington, DC, pp 352-356.

Christie A B 1980 Infectious diseases, 3rd edn. Churchill Livingstone, Edinburgh, pp 47-102.

Clarke D H, Casals J 1958 Techniques for hemagglutination and hemagglutination-inhibition with arthropod-borne viruses. American Journal of Tropical Medicine and Hygiene 7 : 561-573.

Edelman R, Levine M M 1986 Summary of an international workshop on typhoid fever. Reviews of Infectious Diseases 8: 329-349.

Felix A 1944 Technique and interpretation of the Weil-Felix test in typhus fever. Transactions of the Royal Society of Tropical Medicine and Hygiene 37: 321-341.

Gunasegaran K, Lim T W, Ahmed A, Aaskov J G, Lam S K, Pang T 1986 Hemadsorption immunosorbent technique for the detection of dengue immunoglobulin $\mathbf{M}$ antibody. Journal of Clinical Microbiology 23: 170-174.

Kumar R, Malaviya A N, Murthy R G S, Venkataraman M, Mohapatra L N 1974 Immunological study of typhoid: immunoglobulins, $\mathrm{C3}$, antibodies, and leukocyte migration inhibition in patients with typhoid fever and TABvaccinated individuals. Infection and Immunity 10: 12191225.

Lam S K, Chew C B, Poon G K, Ramalingam S, Seow S C, Pang T 1986 Isolation of dengue viruses by intracerebral inoculation of mosquito larvae. Journal of Virological Methods 14: 133-140.

Nardiello S, Pizzella T, Rusoo M, Galanti B 1984 Serodiagnosis of typhoid fever by enzyme-linked immunosorbent assay mens may be difficult (Wicks et al., 1974). Thus, in the present study, high titres were already detectable in some single sera only 3-4 days after the onset of symptoms. IgM titres were measured only to the $\mathrm{H}$ and $\mathrm{O}$ antigens because background $\mathrm{Vi}$ agglutinins are known to be present in the normal populations of endemic areas (Report, 1961). Therefore, measurement of these antibodies is of limited value both in the diagnosis of typhoid and in determination of the carrier state. Within the diagnostic laboratory, the IgM-adherence test could be used directly as a sole serological test or, alternatively, as a confirmatory test following screening of sera by the Widal test. The latter approach would be particularly useful in smaller laboratories, for example those attached to district hospitals, where bacteriological isolation and identification facilities may not be available.

We thank Dr V. How, Department of Medical Microbiology, University of Malaya for providing normal sera. This work was supported by China Medical Board Grant No. 78-374.

determination of anti-Salmonella typhi lipopolysaccharide antibodies. Journal of Clinical Microbiology 20: 718-721.

Pang T, Puthucheary S D 1983 Significance and value of the Widal test in the diagnosis of typhoid fever in an endemic area. Journal of Clinical Pathology 36: 471-475.

Report of the PHLS Working Party on the Bacteriological Examination of Waterworks Employees 1961. Journal of Hygiene 59: 231-247.

Ryan R W, Kwasnik I 1985 Specific immunoglobulin detection. In: Lennette $\mathrm{E} \mathrm{H}$ et al. (eds) Manual of clinical microbiology, 4th edn. American Society for Microbiology, Washington, DC, pp 877-882.

Srivastava L, Srivastava V K 1986 Serological diagnosis of typhoid fever by enzyme-linked immunosorbent assay (ELISA). Annals of Tropical Paediatrics 6: 191-194.

Tsang R S W, Chau P Y 1981 Serological diagnosis of typhoid fever by counterimmunoelectrophoresis. British Medical Journal 282: 1505-1507.

Tsang R S W, Chau P Y, Lam S K, La Brooy J T, Rowley D 1981 Antibody response to the lipopolysaccharide and protein antigens of Salmonella typhi during typhoid infection I. Measurement of serum antibodies by radioimmunoassay. Clinical and Experimental Immunology 46: 508-514.

Watson K C 1957 The relapse state in typhoid fever treated with chloramphenicol. American Journal of Tropical Medicine and Hygiene 6: 72-80.

Wicks A C B, Cruickshank J G, Musewe N 1974 Observations on the diagnosis of typhoid fever in an endemic area. South African Medical Journal 48: 1368-1370.

Winchester R 1976 Tests for detection of the rheumatoid factors. In: Rose N R, Friedman H (eds) Manual of clinical immunology. American Society for Microbiology, Washington, DC, pp 665-668. 